\title{
An Approach to the Classification of Potential Reserve Additions of Giant Oil Fields of the World
}

Open-File Report 2007-1438 


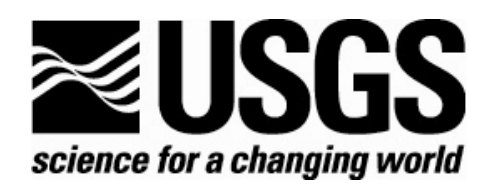

\section{An Approach to the Classification of Potential Reserve Additions of Giant Oil Fields of the World}

By T.R. Klett and M.E. Tennyson

Open-File Report 2007-1438

U. S. Department of the Interior

U.S. Geological Survey 


\title{
U.S. Department of the Interior DIRK KEMPTHORNE, Secretary
}

\author{
U.S. Geological Survey \\ Mark D. Myers, Director
}

U.S. Geological Survey, Reston, Virginia 2008

For product and ordering information:

World Wide Web: http://www.usgs.gov/pubprod

Telephone: 1-888-ASK-USGS

For more information on the USGS - the Federal source for science about the Earth, its natural and living resources, natural hazards, and the environment: World Wide Web: http://www.usgs.gov

Telephone: 1-888-ASK-USGS

Any use of trade, product, or firm names is for descriptive purposes only and does not imply endorsement by the U.S. Government.

Although this report is in the public domain, permission must be secured from the individual copyright owners to reproduce any copyrighted material contained within this report.

Suggested citation:

Klett, T.R., and Tennyson, M.E., 2008, An approach to the classification of potential reserve additions of giant oil fields of the world: U.S. Geological Survey Open-File Report 2007-1438, 28 p. 


\title{
An Approach to the Classification of Potential Reserve Additions of Giant Oil Fields of the World
}

\author{
By T.R. Klett and M.E. Tennyson
}

\section{Foreword}

This report contains notes for slides in a presentation given to the Committee on Sustainable Energy and the Ad Hoc Group of Experts on Harmonization of Fossil Energy and Mineral Resources Terminology on 17 October 2007 in Geneva, Switzerland.

\section{ZUSES}

An Approach to the Classification of Potential Reserves Additions of Giant Oil Fields of the World

\author{
T.R. Klett and M.E. Tennyson
}

U.S. Geological Survey, Box 25046 Denver Federal Center, MS 939, Denver, CO 80225 U.S.A.

United Nations Ad Hoc Group of Experts on Harmonization of Fossil Energy and Mineral Resources Terminology

Geneva, Switzerland

17-19 October 2007

Slide 1. This presentation describes the U.S. Geological Survey (USGS) study to characterize and quantify petroleum-reserve additions, and the application of this study to help classify the quantities. 


\section{Issues}

- Classification of quantities in discovered fields that can be added to reserves (potentially recoverable) is somewhat ambiguous

- U.S. Geological Survey (USGS) broadly classifies these quantities

- Analysis of individual field-development operations and resulting reserve growth may aid in the classification of these potential reserve additions

\section{ZUSGS}

Slide 2. The classification of quantities of petroleum that have the potential to be added to reserves can be ambiguous. The USGS only broadly classifies these quantities. However, analysis of individual field-development operations and resulting reserve growth might aid in the classification of these potential reserve additions. 


\section{Outline}

- Introduction

- USGS Classification

- Field Analysis

- Examples

- Concluding Remarks

Slide 3. The presentation starts with a brief introduction, followed by a description of the USGS classification of petroleum quantities. Next, the approach to the field analysis study is described with some examples of reserve additions from actual field operations. Finally, a database of the reserve additions, which might be used for classification purposes, is demonstrated. 
- Introduction

- USGS Classification

- Field Analysis

- Examples

- Concluding Remarks

\section{Introduction}

- U.S. Geological Survey (USGS) estimates petroleum quantities in BOTH

- Undiscovered accumulations

- Easily classified in UNFC system

- Discovered accumulations, as reserve growth

- Somewhat ambiguous in any classification system

\section{\#USGS}

Slides 4 and 5 . The USGS estimates petroleum resources in both discovered accumulations, in the form of reserve growth, and in undiscovered accumulations. The term "petroleum" is used as a collective term for crude oil, natural gas, natural gas liquids, and condensates. 
Undiscovered resources can be easily classified in the United Nations Framework Classification (UNFC) system. However, resources in discovered accumulations that have the potential to be added to reserves, or recoverable, are not as easily classified. The USGS attributes these additions to reserves as reserve growth and is responsible for estimating these quantities.

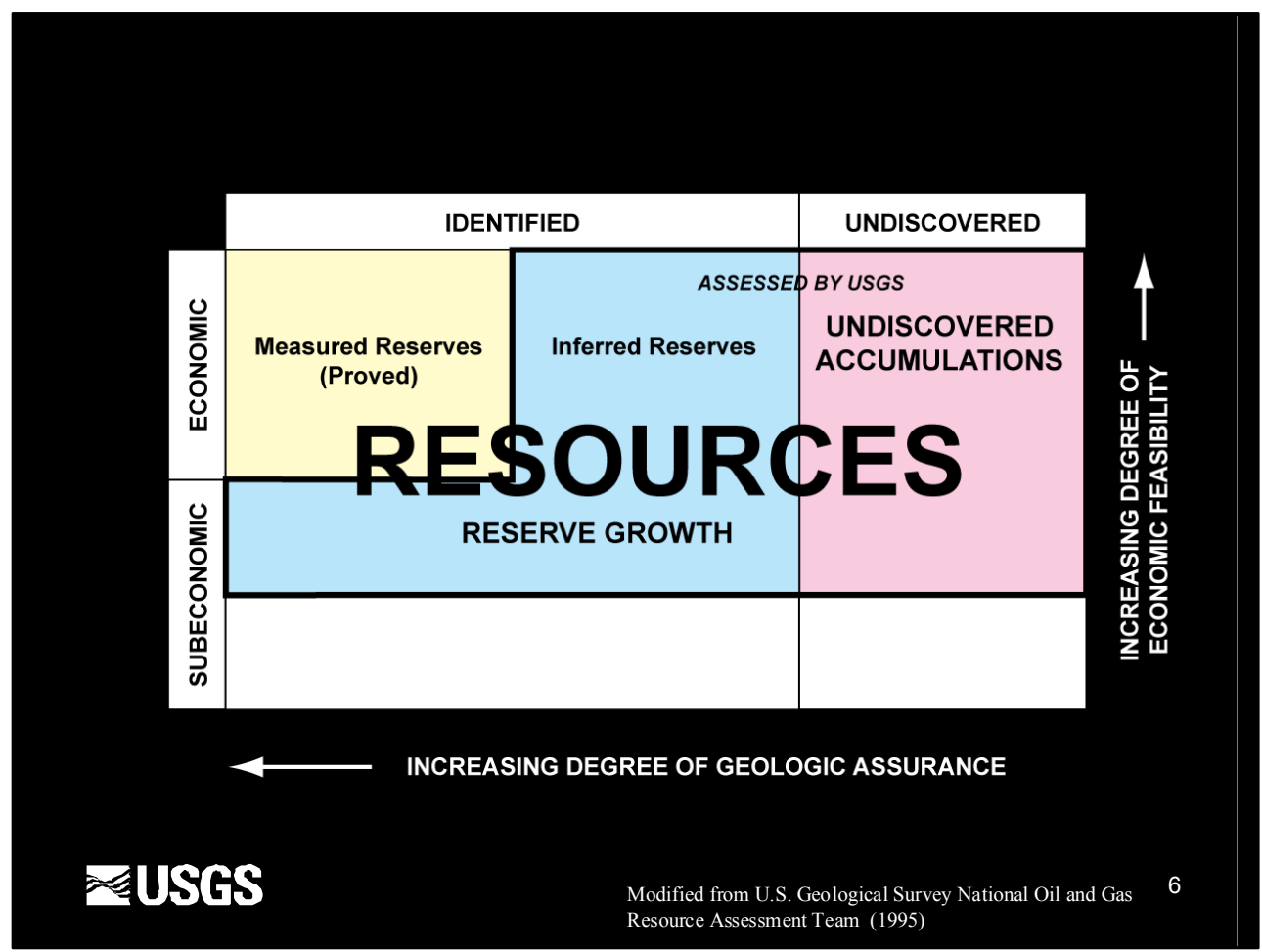

Slides 6 . The USGS only broadly classifies these quantities. This slide shows the classes that contribute to reserve additions. 


\section{Reserve Growth}

Definition

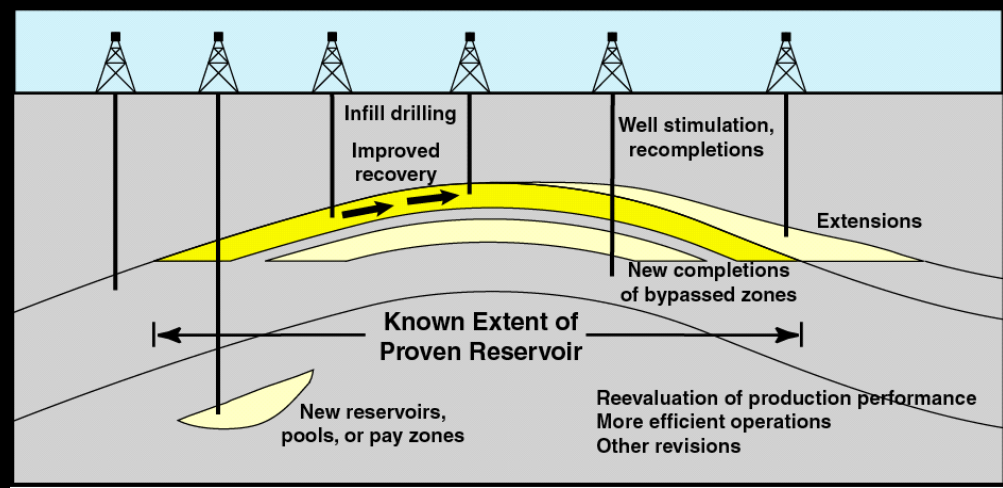

Increases in successive estimates of recoverable volumes of crude

oil, natural gas, and natural gas liquids in discovered fields

- Delineation of additional in-place volumes (geological)

- Increases in recovery efficiency (technological)

- Recalculation of viable reserves in changing conditions (economical) JSES - Economic, operating, and regulatory

Slide 7. Reserve growth is defined as increases in successive estimates of recoverable petroleum quantities in discovered fields. Reserve growth can result from delineation of additional in-place volumes, increases in recovery efficiency, and recalculation of viable reserves in changing economic, operating, and regulatory conditions. 
- Introduction

- USGS Classification

- Field Analysis

- Examples

- Concluding Remarks

\section{USGS Classification}

- USGS evaluates and characterizes geologic assurance and economic feasibility, as in the UNFC, during the course of the petroleumresource assessments

- However, USGS does not have data or a systematic knowledge base of commercial development plans, degree of commitment, and technically feasible projects for the feasibility axis of the UNFC

\section{ZUSGS}

Slides 8 and 9 . The USGS evaluates and characterizes geologic assurance and economic feasibility, as provided in the UNFC, during the course of petroleum-resource assessments. However, the USGS does not have data or a systematic knowledge base for using the feasibility axis of the UNFC, nor 
does it have access to commercial development plans, degree of commitment, or information on technically feasible projects. The use of the feasibility axis is not required, but is indeed offered in the UNFC. However, the UNFC does allow classes to be grouped or expanded.

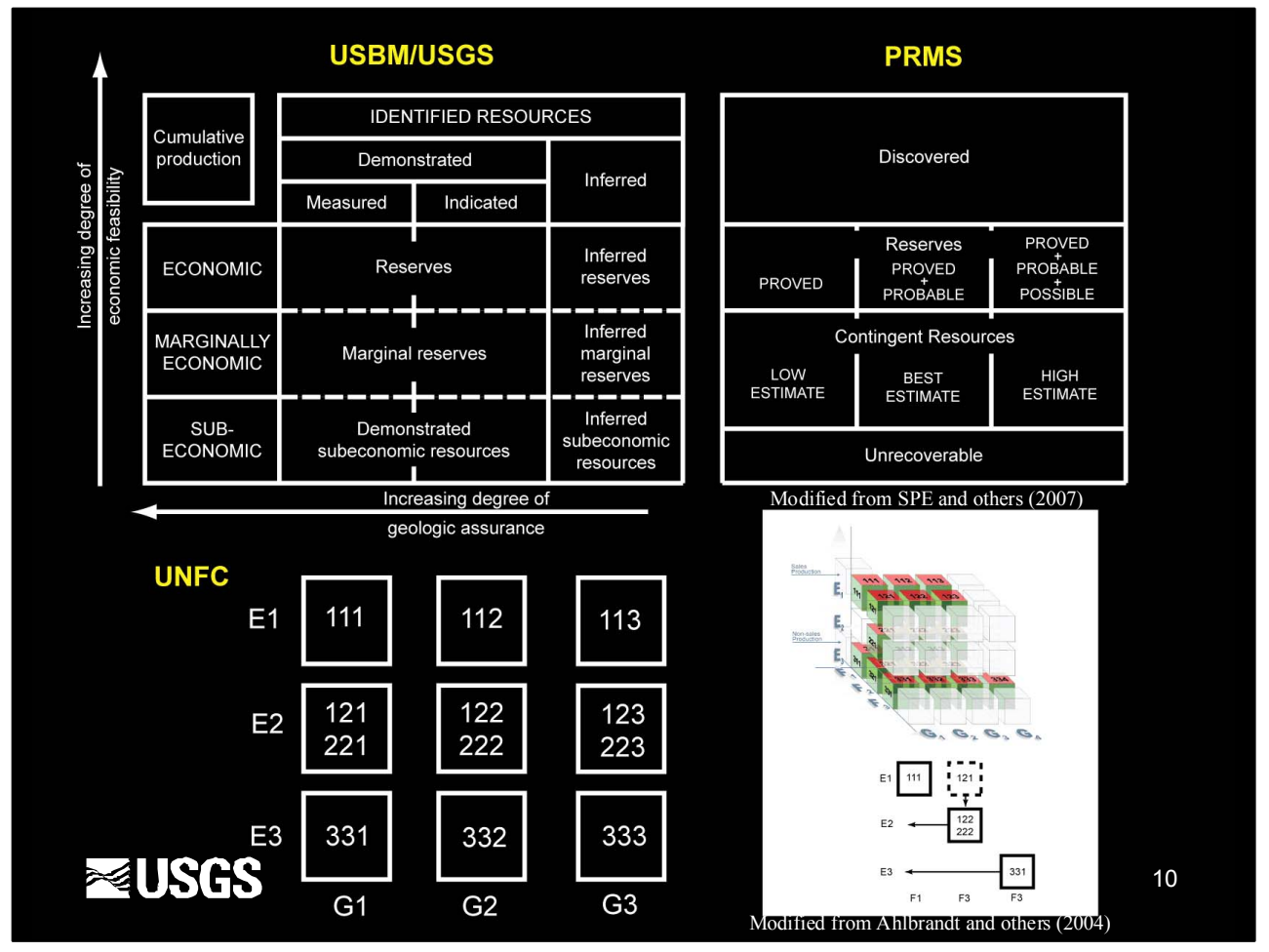

Slide 10. This slide compares three different resource-classification systems. A portion of the McKelvey classification system (U.S. Bureau of Mines and U.S. Geological Survey, 1980) is shown in the upper left, a portion of the Petroleum Resources Management System (PRMS; Society of Petroleum Engineers, World Petroleum Council, American Association of Petroleum Geologists, and Society of Petroleum Evaluation Engineers, 2007) is shown in the upper right, and the UNFC (from Ahlbrandt and others, 2004) is shown below.

The USGS groups the classes on the feasibility axis (lower right). Once grouped, the UNFC cube becomes a two-dimensional system of economic viability versus geologic knowledge (lower left)—similar to the McKelvey classification system.

Categories in the McKelvey system loosely correspond to those of the PRMS and UNFC. Measured reserves correspond to proved reserves (PRMS) and category 111 (UNFC). Likewise, inferred reserves correspond to proved plus probable plus possible reserves of the PRMS and category 113 of the UNFC. 
Classes loosely correspond as well. Reserves correspond to reserves of the PRMS and the three categories of the E1 class of the UNFC. Marginally and subeconomic classes correspond to contingent resources of the PRMS and E2 and E3 classes of the UNFC. Likewise, measured, indicated, and inferred reserves correspond to proved, proved plus probable, and proved plus probable plus possible reserves of the PRMS, respectively. These reserves also correspond to the G1, G2, and G3 classes of the UNFC.

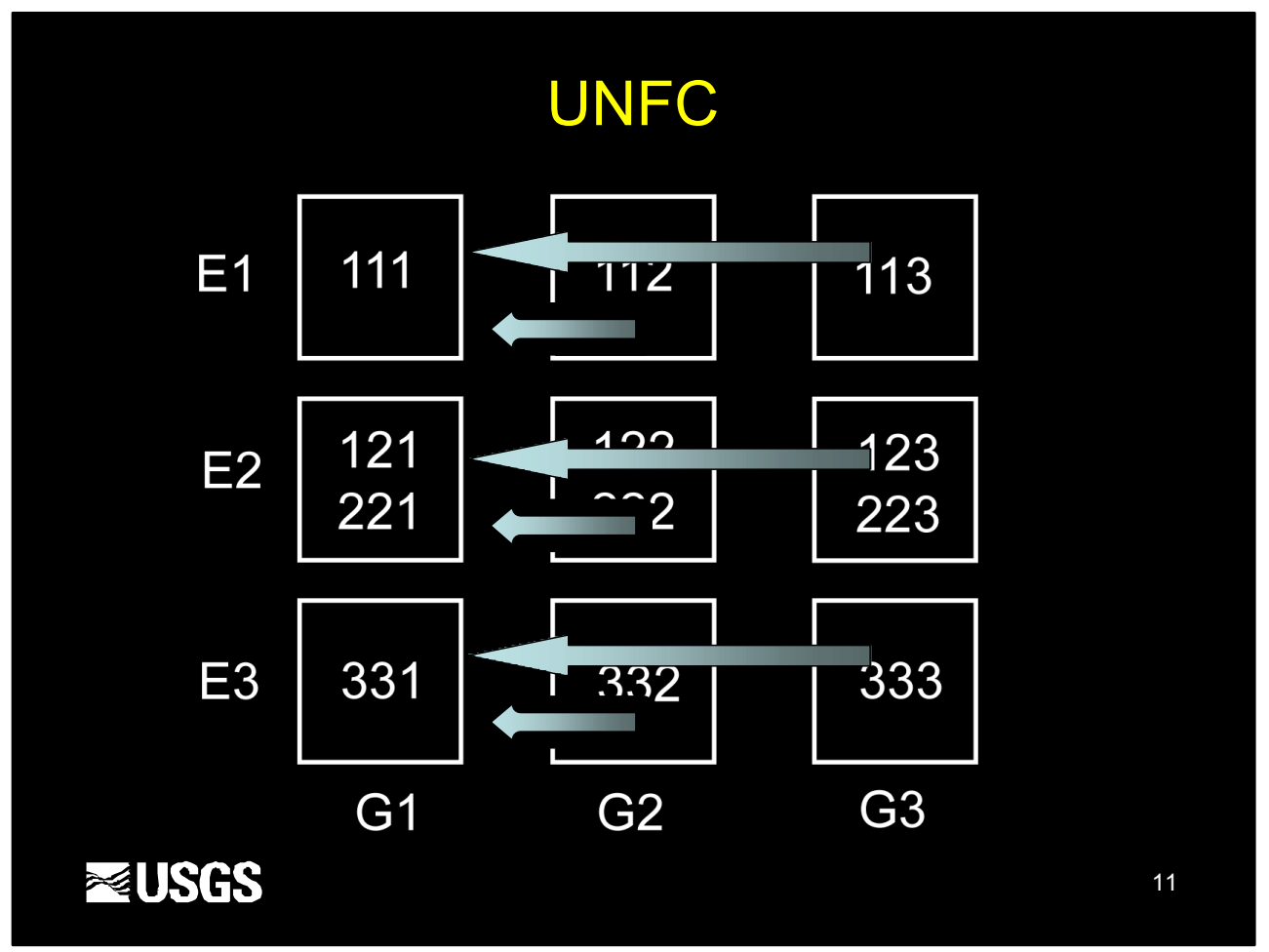

Slide 11. Potential reserve additions are sourced from most of these other reserve and resource classes. These additions might involve increasing geologic knowledge. 


\section{UNFC}

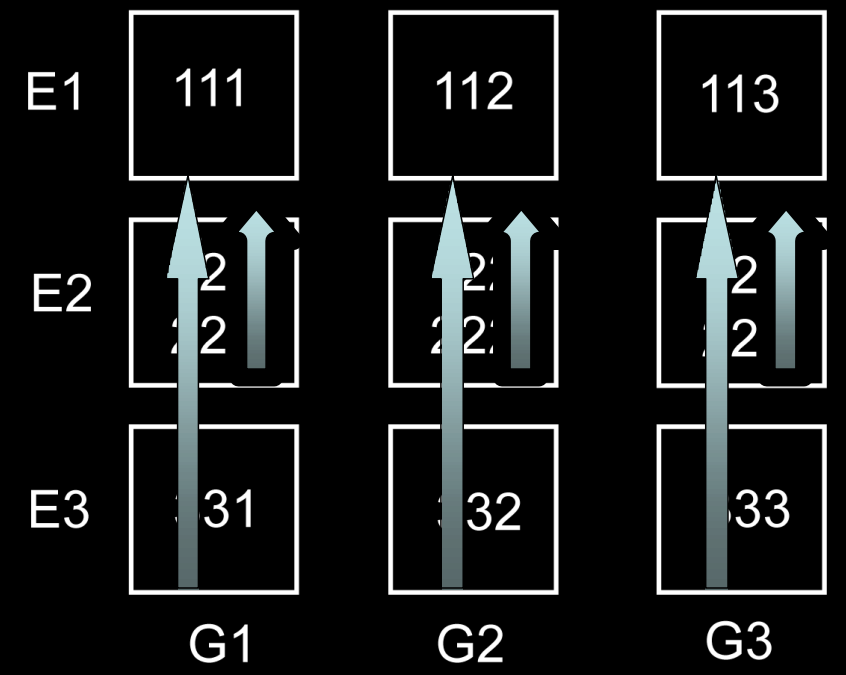

ZUSGS

Slide 12. Or, these additions might involve increasing economic viability. The path to recovery can be quite complex. 
- Introduction

- USGS Classification

- Field Analysis

- Examples

- Concluding Remarks

\section{Approach}

- Compile and analyze field-history data for large oil and gas fields of the world

- World's largest oil fields

- 54 of the 56 oil fields containing $=5 \times 10^{9}$ barrels of recoverable oil

- Giant U.S. oil fields

- $=500 \times 10^{6}$ barrels of recoverable oil

\section{\#USGS}

Slides 13. and 14. As a first step to resource classification, one can try to track the paths by examining individual fields. The USGS is compiling and analyzing field-history data for large oil and gas fields of the world, starting with the largest oil fields. So far, 54 of the 56 oil fields containing more than 5 
billion barrels of recoverable crude oil were studied. The other two fields are aggregations of many smaller fields and are analyzed at this time.

Many U.S. oil fields containing more than 500 million barrels (MMB) of recoverable crude oil, as well as several other smaller oil fields, were also studied.

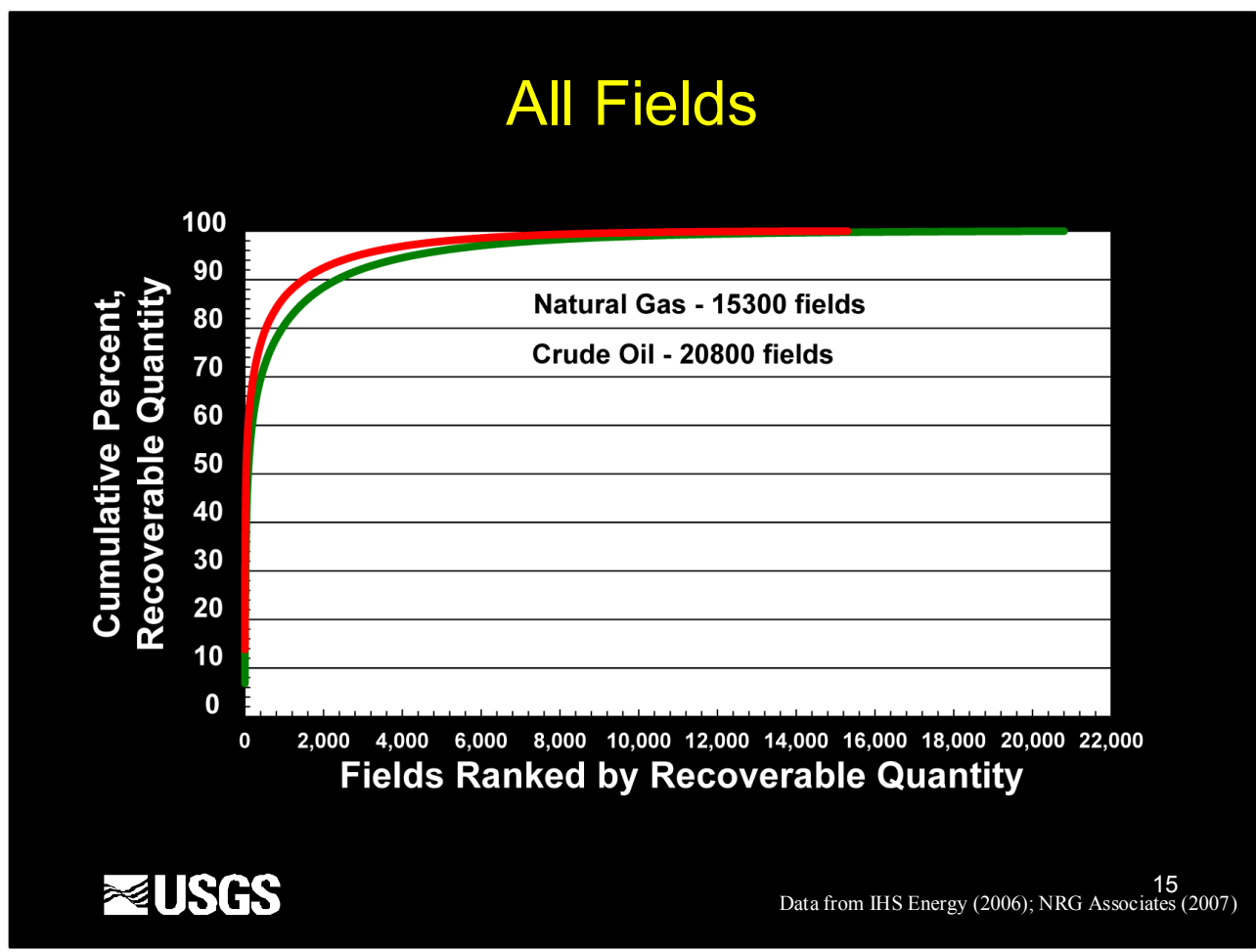

Slide 15. In order to prioritize the fields for this study, the oil and gas fields of the world were ranked by recoverable petroleum quantities. Recoverable quantity is used as a measure of field size. Fields are analyzed in order of decreasing size. This slide shows the rank of the world's fields, except for Canadian fields whereby only 165 fields are represented in this graph. In this and the next three slides, the vertical axis represents the cumulative percent of the world's known recoverable crude oil and natural gas quantities. The horizontal axis represents the fields ranked in order of decreasing recoverable quantity. The red curve represents gas fields (fields containing greater than 20,000 cubic feet of natural gas per barrel of crude oil). The green curve represents oil fields (fields containing less than 20,000 cubic feet of natural gas per barrel of crude oil). Our database contains approximately 15, 300 gas fields and 20,800 oil fields. 


\section{Fields $=5 \times 10^{9}$ Barrels Oil Equivalent}

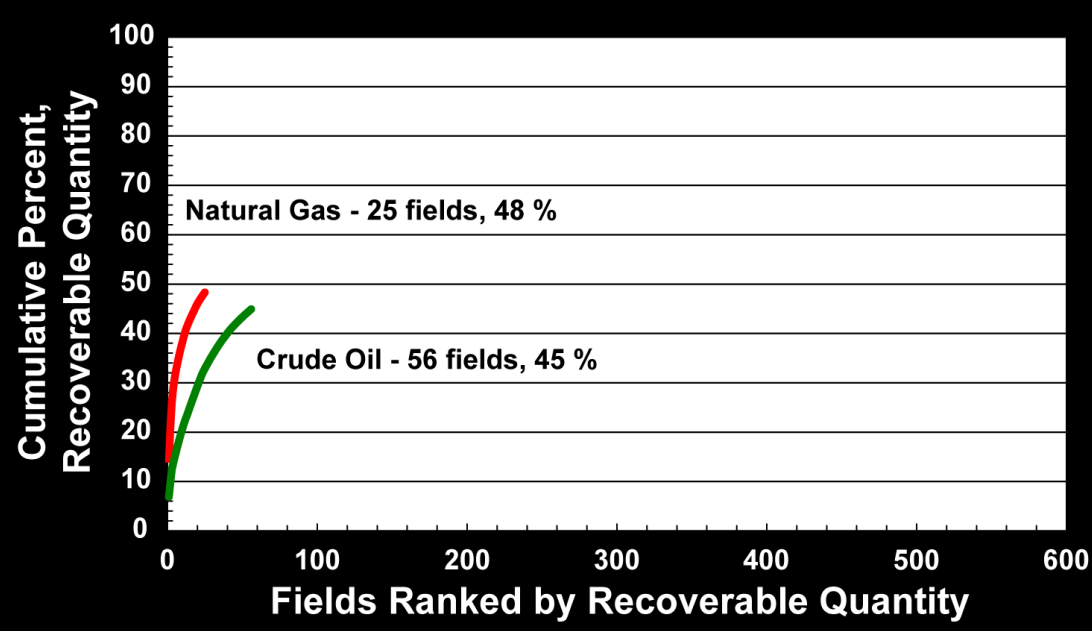

Slide 16. This slide shows the world's fields that contain greater than or equal to 5 billion barrels of crude oil equivalent (BBOE) and thus shows the oil fields we analyzed so far. The slide also shows gas fields of comparable size. The 56 oil fields shown contain approximately 45 percent of the world's known crude oil, and 25 gas fields contain approximately 48 percent of the world's known natural gas. 


\section{Fields $=1 \times 10^{9}$ Barrels Oil Equivalent}

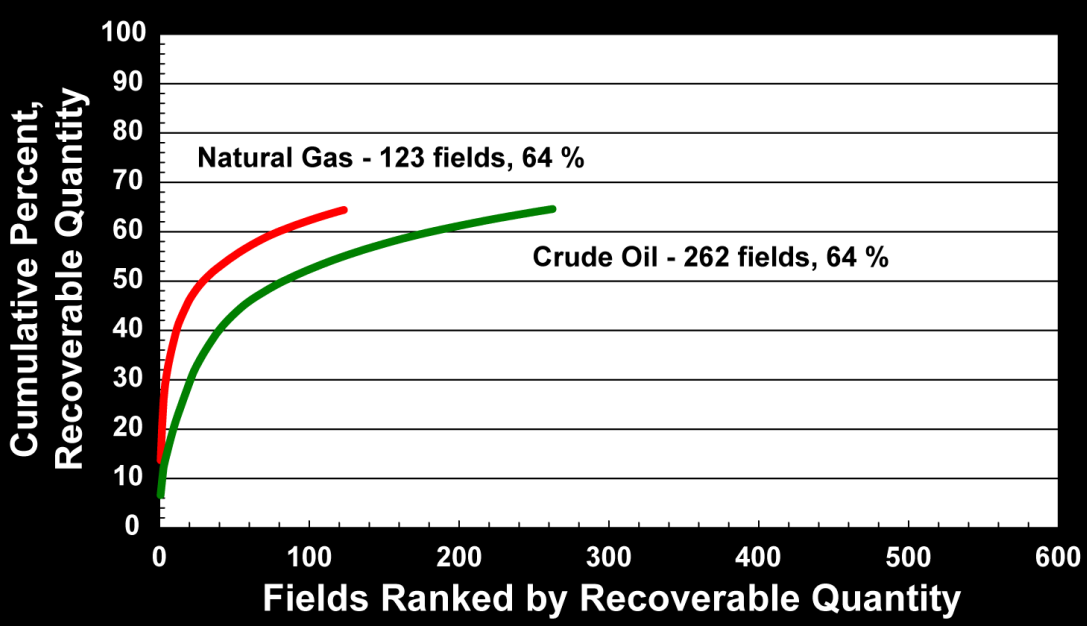

Slide 17. This slide shows fields greater than or equal to $1 \mathrm{BBOE}$. The next group of fields planned for analysis (another 206 fields) is in this population. Two hundred and sixty-two oil fields contain approximately 64 percent of the world's known crude oil and 123 gas fields contain approximately 64 percent of the world's known natural gas. 


\section{Fields $=0.5 \times 10^{9}$ Barrels Oil Equivalent}

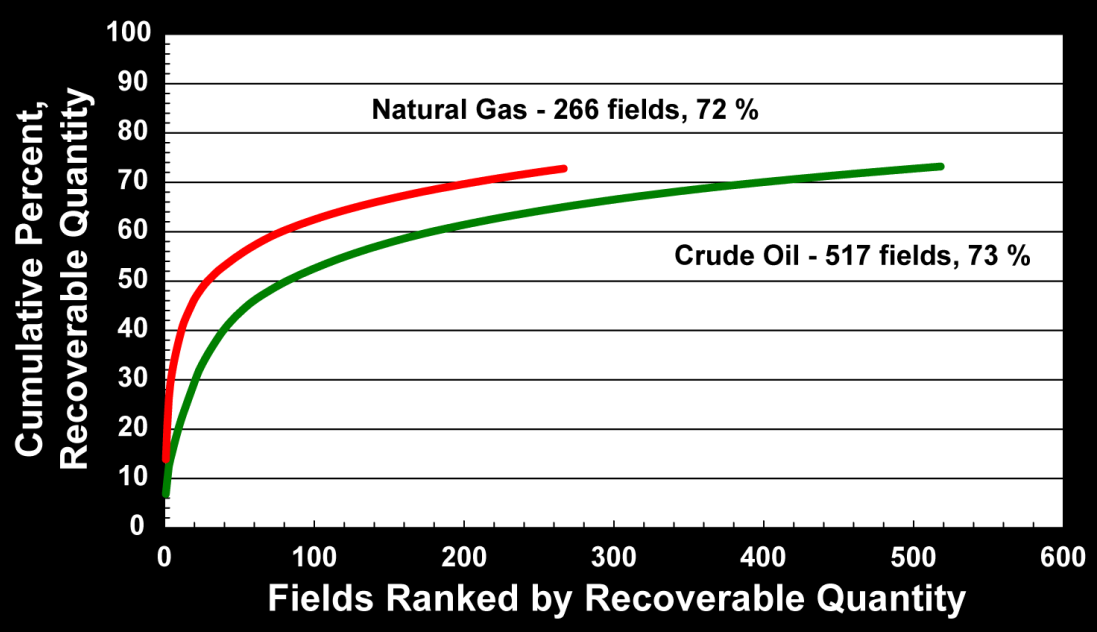

Slide 18. This slide shows fields greater than or equal to $0.5 \mathrm{BBOE}-$ fields considered as giants. To evaluate this population, another 311 oil fields in addition to the 56 fields in the first group and the 206 fields in the second group will be studied. Five hundred and seventeen oil fields and 266 gas fields contain almost three-fourths of the world's known crude oil and natural gas. 


\section{Approach}

- Database

- Individual fields

- Field operations

- Absolute and relative additions to reserves

Slide 19. A database can be constructed of individual fields with field operations and associated reserve additions, as both absolute and relative quantities. Data for this study are obtained by analyzing historic estimates of production and reserves and relating these estimates to field operations. 


\section{Field Analysis}

- Field definition

- Annual production

- In-place quantities

- Cumulative production

- Remaining reserves

- Recoverable quantities

- Field-operation history

- Cumulative production $=$ Sum annual production

- Recoverable quantity = Cumulative production + Remaining reserves

Slide 20. Production and reserve quantities are from published reports and proprietary commercial databases. These quantities include (1) annual production, (2) in-place quantities, (3) cumulative production, (4) remaining reserves, (5) recoverable quantities, and (6) field-operation history. Some quantities can be calculated from others, such as cumulative production, which is a summation of annual production. Also, recoverable quantities can be calculated by adding cumulative production and remaining reserves. 


\section{Analysis of Field Data}

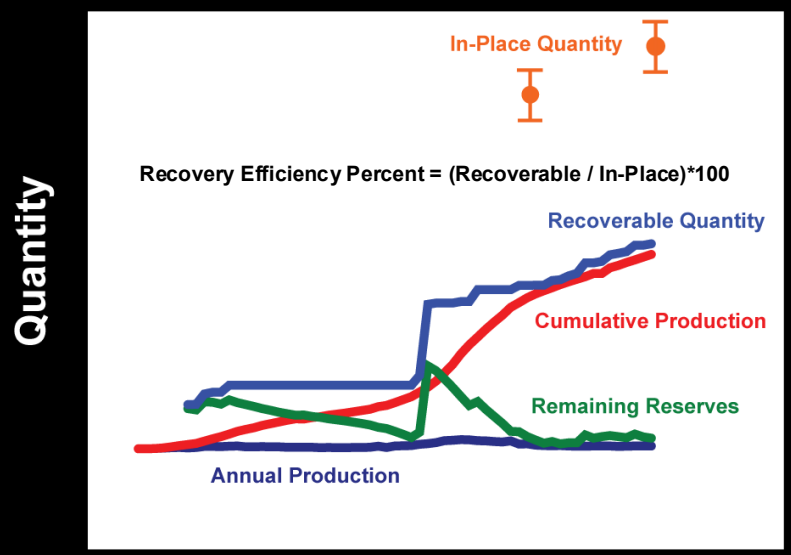

\section{Time}

\section{Analysis of Field Data}

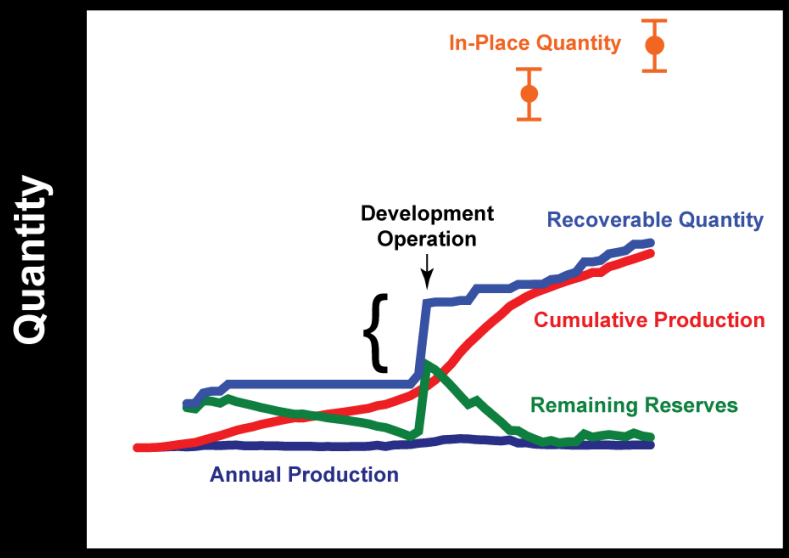

Time

Slides 21 and 22 . When plotted by time, a set of curves is generated that characterize field-development history. Data are obtained by simply measuring increases in recoverable quantities and remaining reserves, and relating these increases to an operation. 
The concept of reserve growth occurs between the recoverable and in-place quantities. Recoverable quantities are used as the reference for reserve growth because reserves are components of recoverable quantities.

- Introduction

- USGS Classification

- Field Analysis

- Examples

- Concluding Remarks 

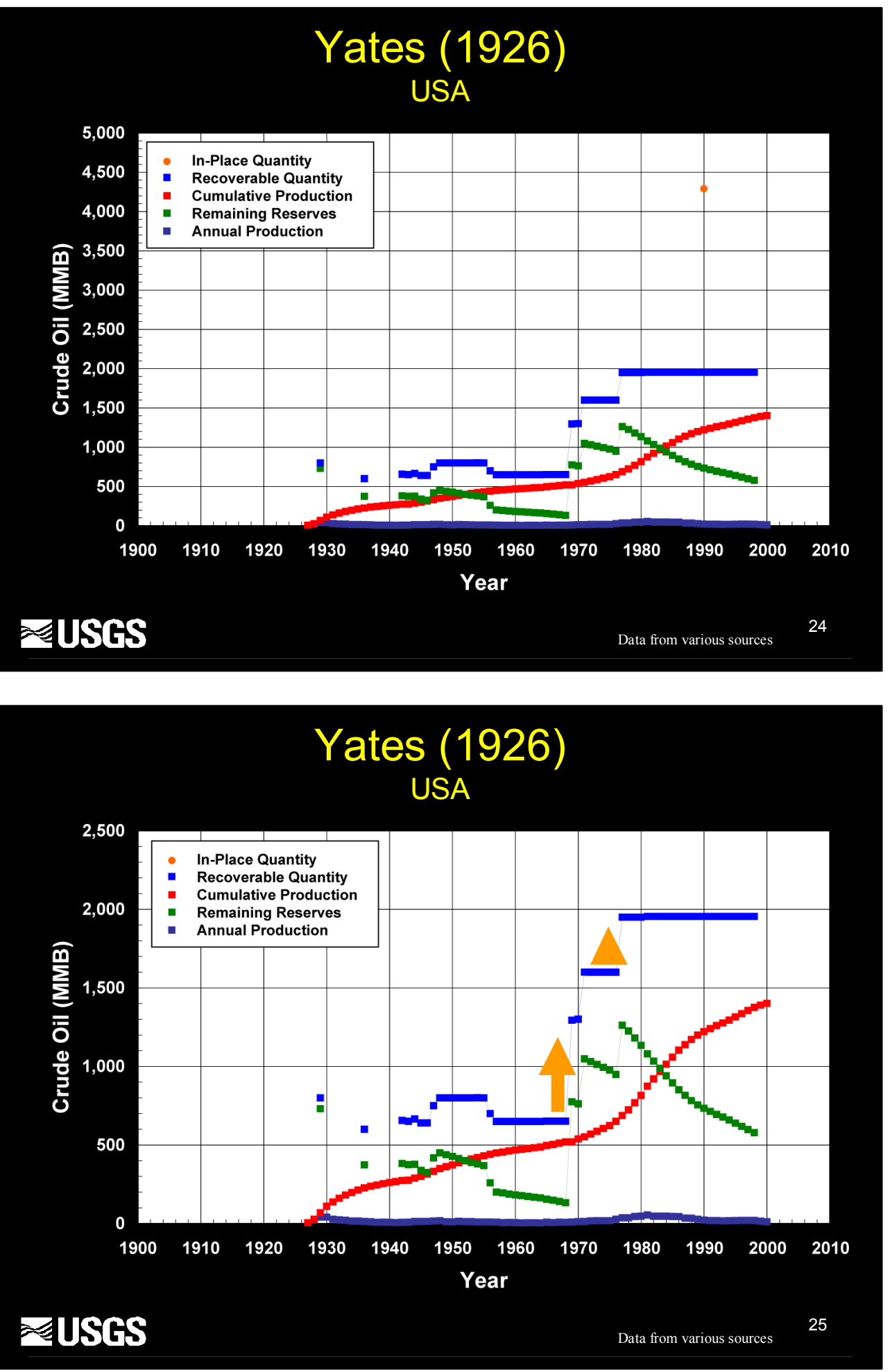

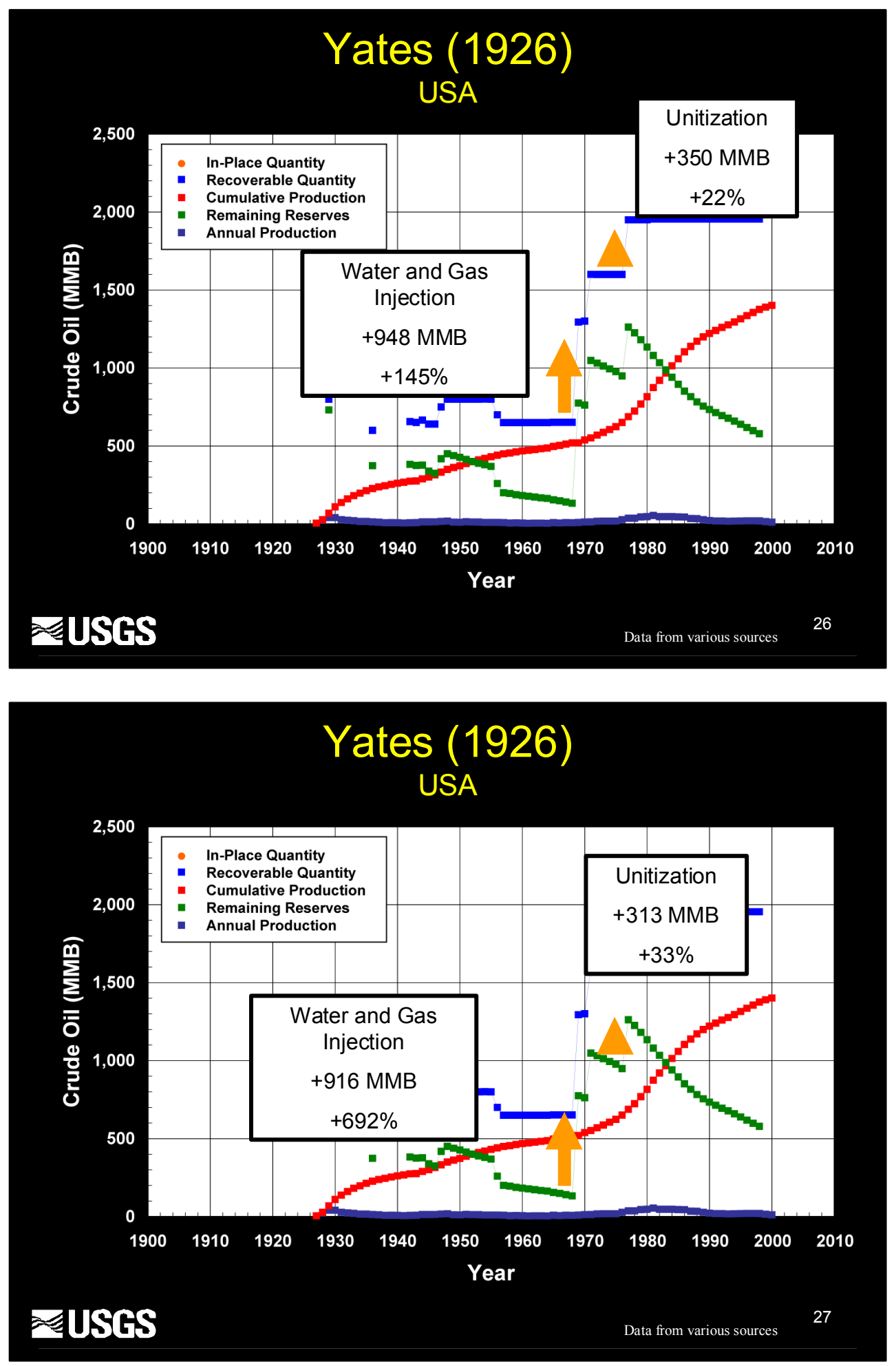

Slides 23 through 27 . The next several slides show an example of fieldhistory analysis. The field-development history of the giant Yates oil field of western Texas is shown. This field was discovered in 1926. Raw data are shown to illustrate the complexity of field histories and inconsistencies 
among different data sources, for example, published and commercial data. Not all increases in recoverable quantities can be related to field operations.

Annual production, cumulative production, remaining reserves, recoverable quantities, and in-place quantities are plotted. When in-place quantities are removed, the remaining quantities can be replotted at a larger scale to show more detail. Several increases in recoverable quantities and remaining reserves can be seen. Two of these increases can be related to the implementation of field-development operations. These are water and gas injection in the late 1960s and unitization in the mid-1970s. Recoverable crude oil increased by $948 \mathrm{MMB}$ (145 percent) and $350 \mathrm{MMB}$ (22 percent), respectively. Likewise, remaining crude oil reserves increased by $916 \mathrm{MMB}$ (692 percent) and 313 MMB (33 percent), respectively. Similar observations are made on other large oil fields of the world.

\begin{tabular}{|l|l|l|l|l|}
\hline Field & Years & Operation & $\begin{array}{l}\text { Increase } \\
\text { (MMB) }\end{array}$ & $\begin{array}{l}\text { Increase } \\
\text { (percent) }\end{array}$ \\
\hline Marun (1964) & $1986-1987$ & Gas injection & 300 & 2 \\
\hline Umm Shaif (1958) & $1993-1996$ & Gas injection & 620 & 11 \\
\hline Zuluf (1965) & $1992-1993$ & Capacity expansion & 3360 & 32 \\
\hline Marjan (1967) & $1991-1992$ & Capacity expansion & 1774 & 80 \\
\hline Priobskoye (1982) & $1992-1993$ & Water injection & 3025 & 4033 \\
\hline Rumaila (1953) & $1996-2001$ & Water injection & 1800 & 8 \\
\hline Yates (1926) & $1968-1971$ & Water and gas inj. & 948 & 145 \\
\hline Wasson (1936) & $1969-1971$ & In-fill drilling & 830 & 128 \\
\hline Wasson (1936) & $1983-1985$ & Carbon dioxide inj. & 250 & 12 \\
\hline Slaughter-L (1936) & $1975-1977$ & Carbon dioxide inj. & 293 & 26 \\
\hline
\end{tabular}

Slide 28. Data from these field analyses are tabulated and various statistics can be calculated, such as the range and mean of increases in recoverable quantities. For example, statistics can be obtained on the relative increases of gas injection versus water injection, or gas injection during the 1980s versus the 1990s. 
- Introduction

- USGS Classification

- Field Analysis

- Examples

- Concluding Remarks

\section{Classification of Quantities}

- Quantities are assets

- Infill or development drilling - G2 and/or G3?

- Extensions and new reservoirs - E2 or E3?

- Improved recovery operations (floods, recompletions) - Combination of categories?

- USGS does not have data to answer these questions at this point in time

\section{ZUSGS}

Slides 29 and 30 . The volumes of petroleum that contribute to reserve additions or increases in recoverable quantities are assets. But how should these quantities be classified? Given enough information, one might presume that quantities added by infill or development drilling are from the 
G2 and G3 classes (112 and 113 categories of the UNFC or possible and probable reserves of the PRMS). Likewise, one might presume that quantities added by extensions and new reservoirs are from the E2 and E3 classes $(221,222,223,311,312,313,321,322$, and 323 categories of the UNFC or contingent resources of the PRMS). Also, one might presume that added recoverable quantities by improved recovery operations (floods, recompletions) are from a combination of the other reserve and resource categories and classes.

\section{Concluding Remarks}

- USGS estimates quantities added to reserves

- Individual field analysis may be a first step to aid in the classification of these additional quantities

Slide 31 . Although the USGS only broadly classifies the sources of potential reserve additions, it is responsible for estimating these quantities. Relating increases in reserve and recoverable quantities to field operations might be a first step to aid in the classification of these additional quantities. 


\title{
Thank You for Your Interest
}

\author{
tklett@usgs.gov
}

\author{
http://energy.usgs.gov/
}

Slide 32. Thank you for your interest.

\section{References Cited}

Ahlbrandt, T.S., Blaise, J.R., Blystad, P., Kelter, D., Gabrielyants, G., Heiberg, S., Martinéz, A., Ross, J.G., Slavov, S., Subelj, A., and Young, E.D., 2004, Updated United Nations Framework Classification for reserves and resources of extractive industries: Society of Petroleum Engineers Paper SPE 90839, presented at SPE Annual Technical Conference and Exhibition, Houston, Texas, 26-29 September, $7 \mathrm{p}$.

IHS Energy, 2006, [includes data current through December, 2006], International petroleum exploration and production database: IHS Energy; database available from IHS Energy, 15 Inverness Way East, Englewood, Colorado 80112 USA.

Klett, T.R., 2005, United States Geological Survey's reserve-growth models and their implementation: Natural Resources Research, v. 14, no. 3 (September 2005), p. 249-264. 
NRG Associates, 2007, [includes data current through December, 2005], The Significant Oil and Gas Fields of the United States: NRG Associates, Inc.; database available from NRG Associates, Inc., P.O. Box 1655, Colorado Springs, CO 80901, U.S.A.

Society of Petroleum Engineers, World Petroleum Council, American Association of Petroleum Geologists, and Society of Petroleum Evaluation Engineers, 2007, Petroleum Resources Management System: available on the Worldwide Web at www.spe.org.

U.S. Bureau of Mines and U.S. Geological Survey, 1980, Principles of a Reserve/Resource Classification for Minerals: U.S. Geological Survey Circular 831, 5 p.

U.S. Geological Survey National Oil and Gas Resource Assessment Team, 1995, 1995 National assessment of United States oil and gas resources: U.S. Geological Survey Circular 1118, 20 p. 